\title{
Adverse Effects of Hydroalcoholic Extracts and the Major Components in the Stems of Impatiens balsamina L. on Caenorhabditis elegans
}

\author{
Hong-Fang Jiang, ${ }^{1,2}$ Zi-Heng Zhuang, ${ }^{3}$ Bei-Wei Hou, ${ }^{2}$ Bao-Jun Shi, ${ }^{2}$ Cheng-Jie Shu, \\ Lei Chen, ${ }^{2}$ Guo-Xin Shi, ${ }^{1}$ and Wei-Ming Zhang ${ }^{1,2}$ \\ ${ }^{1}$ College of Life Science, Nanjing Normal University, Nanjing 210046, China \\ ${ }^{2}$ Nanjing Institute for Comprehensive Utilization of Wild Plant, Nanjing 210042, China \\ ${ }^{3}$ School of Pharmaceutical Engineering and Life Sciences, Changzhou University, \\ Changzhou 213264, China \\ Correspondence should be addressed to Guo-Xin Shi; gxshi@njnu.edu.cn and Wei-Ming Zhang; botanyzh@163.com
}

Received 20 July 2016; Revised 24 October 2016; Accepted 22 December 2016; Published 23 February 2017

Academic Editor: Nunziatina De Tommasi

Copyright (C) 2017 Hong-Fang Jiang et al. This is an open access article distributed under the Creative Commons Attribution License, which permits unrestricted use, distribution, and reproduction in any medium, provided the original work is properly cited.

\begin{abstract}
Impatiens balsamina L. (Balsaminaceae), an annual herb found throughout China, has been extensively used in traditional Chinese medicine (TCM). However, our knowledge regarding the adverse effects of I. balsamina in vivo is very limited. In this present study, the nematode Caenorhabditis elegans model was employed to fully assess the adverse effects of hydroalcoholic (EtOH 55\%) extracts of I. balsamina stems (HAEIBS) in vivo. After exposure to $10 \mathrm{mg} / \mathrm{mL}$ HAEIBS, the major organism-level endpoints of C. elegans of percent survival, frequency of head thrash and body bends, and reproduction had decreased by $24 \%, 30 \%$, and $25 \%$, respectively. The lifespan of $C$. elegans was also greatly reduced after HAEIBS exposure compared to the controls. The active compounds in HAEIBS were separated using high speed countercurrent chromatograph (HSCCC) and characterized by high performance liquid chromatography (HPLC) and nuclear magnetic resonance (NMR). Two compounds, lawsone and 2-methoxy-1,4-naphthoquinone (MNQ), and their adverse effects were then more thoroughly detailed in this study. It was found that lawsone is the major toxin in HAEIBS with a higher toxicity than MNQ in terms of negative impact on C. elegans mortality, locomotion, reproduction, and lifespan. Our data also suggests that the C. elegans model may be useful for assessing the possible toxicity of other Chinese medicines, plant extracts, and/or compounds.
\end{abstract}

\section{Introduction}

Impatiens balsamina L. (Balsaminaceae) is an annual herb found throughout China. Water extracts of I. balsamina stems have long been used in Chinese traditional medicine (TCM) for treatment of a wide range of diseases and ailments, including rheumatism, isthmus, generalized body aches, fractures, and fingernail inflammation [1]. A number of compounds have been isolated from the stems of I. balsamina and identified, for example, flavonols [2], naphthoquinones $[3,4]$, anthocyanin [5], and several phenolic compounds [6], and have been shown to have beneficial properties, for example, antioxidant [7], antimicrobial [8], antitumor $[9,10]$, antianaphylactic [11], anti-inflammatory [12], antipruritic [13], and antinociceptive [14].

Although the use of I. balsamina stems has many medical benefits, it may also cause some adverse reactions. For example, long-term exposure to I. balsamina stems extracts and compounds has been found to be mildly toxic to several cancer cell lines $[15,16]$. Due to this potential toxicity, it is prohibited to prescribe "Tougucao," a well-known TCM, which is dried aerial stems of I. balsamina, to pregnant women [1].

Caenorhabditis elegans is a well-known, nonmammalian, alternative animal model that is extensively used in biomedical and toxicological research $[17,18]$, including assessments 
of toxicity. Several studies have tested for beneficial and/or adverse effects of compounds isolated from certain plants and Chinese medicines in C. elegans [19-23]. This is primarily due to the several advantages of using C. elegans, including their short life cycle, ease of handling, small body size, and high sensitivity to toxins and toxicants $[17,24-26]$. In addition, the genome is highly conserved between C. elegans and mammals, including humans. This level of similarity implies that any assessment of toxicity performed in C. elegans might not only be comparable to assessments in other mammalian models, but also applicable to clinical populations $[17,18,27]$. For example, a series of studies found that the toxicity of toxins in C. elegans was similar to that observed in mammals $[17,28]$, implying that the results of toxicological studies performed in C. elegans will closely reflect the effects in mammalian models for the majority of compounds tested.

Currently, little is known about the in vivo toxicity and chemical composition of any toxic substances in hydroalcoholic extracts of I. balsamina stems (HAEIBS). In this present study, the toxicity of HAEIBS was evaluated in C. elegans based on a series of endpoints. To identify the potential compound(s) causing HAEIBS toxicity, we isolated compounds from I. balsamina stems using high speed countercurrent chromatography (HSCCC) and then assessed the toxicity of these individual compounds in C. elegans. The results of this study will increase our understanding of the in vivo toxicity of I. balsamina stems.

\section{Materials and Methods}

2.1. Plant Samples and Chemicals. Impatiens balsamina L. (Balsaminaceae) plants were collected in July 2014 and authenticated by Dr. Jiu Zhang (Nanjing Institute for Comprehensive Utilization of Wild Plants). A voucher specimen (number 140628) was deposited at the Herbarium of Nanjing Institute for Comprehensive Utilization of Wild Plants. The stems of I. balsamina were collected, freeze-dried, and stored at $4^{\circ} \mathrm{C}$. All chemicals used in this study were purchased from Sigma-Aldrich (St. Louis, MO, USA).

2.2. Preparation of Impatiens Balsamina L. Hydroalcoholic Extracts. Hydroalcoholic was used in our study for the extraction of $I$. balsamina stems based on preliminary experiments demonstrating extractions with 55\% ethanol yielded a higher concentration of bioactive substances than extractions with water.

To make HAEIBS, freeze-dried I. balsamina stems (50 g) were ground up and passed through a 60-mesh screen to obtain a fine powder and then extracted twice with $400 \mathrm{~mL}$ of $55 \%$ ethanol with refluxing for 1 hour. The extracting solution was then passed through three layers of filter paper and concentrated by decompressive rotary evaporation at $60^{\circ} \mathrm{C}$. The concentrated extracts were completely dried in a freezedrier and stored at $-20^{\circ} \mathrm{C}$ until later use.

2.3. Nematode Maintenance and Assessments of HAEIBS Toxicity. The C. elegans wild-type strain N2 was used in this study. C. elegans were maintained on plates containing nematode growth medium (NGM) and Escherichia coli OP50 at $20^{\circ} \mathrm{C}$ as previously described [29]. Age synchronous populations of L1 or L4 larvae were obtained using a previously published method [30]. Nematodes at different life stages were exposed to HAEIBS for 48 hours in 12 -well plates containing sterile $\mathrm{K}$ medium (50 mM NaCl, $30 \mathrm{mM} \mathrm{KCl}$, and $10 \mathrm{mM} \mathrm{NaOAc}, \mathrm{pH}$ 5.5) and E. coli OP50 at $20^{\circ} \mathrm{C}[30,31]$. Nematodes exposed to HAEIBS were then assessed for indicators of toxicity, including lethality, decreases in locomotion, and reduced reproduction (brood size).

The HAEIBS stock solution $(500 \mathrm{mg} / \mathrm{mL})$ was prepared in DMSO and then diluted in $\mathrm{K}$ medium to a final concentration of $0.1-10 \mathrm{mg} / \mathrm{mL}$ before plating. For lawsone and MNQ, the final concentrations were $0.1-0.5 \mathrm{mg} / \mathrm{mL}$. E. coli OP50 was spread on the NGM plates as food for the nematodes.

Lethality was evaluated as the percent survival of the population based on a previously described method [32]. Fifty L1 larvae stage C. elegans were treated with different concentrations of HAEIBS for 48 hours. Nematodes were considered dead if, while observing under a dissecting microscopy, they failed to respond to mechanical stimulation from a small metal wire. Three replicates were performed for each cohort.

Locomotion was assessed based on both head thrashing and body bending $[30,31]$. To assay head thrash, the control and HAEIBS-treated nematodes were washed with $\mathrm{K}$ medium and then transferred to a microtiter well containing $60 \mu \mathrm{L}$ of $\mathrm{K}$ medium on top of the agar. After a 1 min recovery period, the number of head thrashes was counted for $1 \mathrm{~min}$, where a thrash was defined as a change in the direction of bending at the mid body. To assay body bend, the nematodes were then placed onto a second plate and the number of body bends was counted for 20 seconds, where a body bend was defined as a change in the direction in the area corresponding to the posterior bulb of the pharynx along the $y$-axis, assuming that the nematode was traveling along the $x$-axis. Three replicates of 15 nematodes were examined for each treatment group.

Reproduction was assessed based on brood size, which was determined as the number of offspring at all stages beyond the egg stage. Nematodes were transferred daily to new agar plates until the end of the egg laying period. Hatched progeny were allowed to grow to the L1/L2 stage and then counted manually. Three replicates of 10 nematodes each were examined for each treatment group.

The lifespan assay was performed as previously described $[33,34]$. Briefly, after treating the nematodes for 48 hours starting at the L1 larvae stage, the nematodes were transferred daily to new plates for the first 4 days of adulthood. Nematode viability was checked daily and the nematodes were considered dead when they failed to move after repeated mechanical stimulation with a small metal wire. Fifty nematodes were examined for each treatment group. All graphs display an average of three independent trials.

2.4. HAEIBS Chemical Component Isolation and Identification. HAEIBS $(15 \mathrm{~g})$ was diluted in $2 \mathrm{~L}$ water and then extracted five times with water-saturated light petroleum (b.p. 60-90 C) and ethyl acetate in succession. After analysis 
by thin layer chromatography (TLC) and high performance liquid chromatography (HPLC), the ethyl acetate fraction was incubated under a vacuum until completely dry and stored at $-4^{\circ} \mathrm{C}$ for subsequent isolation and separation by HSCCC (TBE-300A, Tauto Biotech., Shanghai, China) (nhexane: ethyl acetate: methanol: water $=5: 4: 4.5: 5(\mathrm{v} / \mathrm{v})$, upper organic phase as the stationary phase, lower aqueous phase as the mobile phase, and flow rate: $1.0 \mathrm{~mL} / \mathrm{min}$, $850 \mathrm{rpm}$, forward). The effluent from the column outlet was continuously monitored at $280 \mathrm{~nm}$. Peak fractions were collected according to the chromatogram and then incubated under a vacuum. A total of 4 peaks, peaks I $(4.5 \mathrm{mg})$, II (10.5 mg), III (13.6 mg), and IV (43.6 mg), were obtained with purities of $96.5,95.2,96.8$, and $98.3 \%$, respectively, as determined by HPLC-DAD. Each peak fraction was identified using Agilent 1100/MSD electron impact mass spectrometry (EI-MS) (Agilent, California, USA) and a BRUCKER AVANCE 500 nuclear magnetic resonance (NMR) spectrometer (BruckerBioSpin Inc., Switzerland).

2.5. Characterization of HAEIBS by HPLC. Crude HAEIBS samples were analyzed with an Agilent 1200 HPLC system (California, US) using a ZORBAX XDB- $\mathrm{C}_{18}$ column (150 $\times 4.6 \mathrm{~mm}$ i.d., $5 \mu \mathrm{m}$ ) set at $25^{\circ} \mathrm{C}$. The mobile phase was a solution of acetonitrile-2.5\% aqueous acetic acid delivered at a flow rate of $1.0 \mathrm{~mL} / \mathrm{min}$ with a gradient elution of $0-10 \mathrm{~min}$, $25: 75 ; 10-20 \mathrm{~min}, 32: 68$; and $20-35 \mathrm{~min}, 55: 45$. Samples were injected in a $20 \mu \mathrm{L}$ volume. The detection wavelength was set at $280 \mathrm{~nm}$.

Separate stock solutions were made in methanol of lawsone, quercetin, $\mathrm{MNQ}$, and kaempferol for the reference standards. A working solution of each standard was prepared in methanol and then diluted to provide a series of standard solutions at concentrations of 50,40,25, 12.5, 10, 6.25, and $3.125 \mu \mathrm{g} / \mathrm{mL}$. The standard curve equations are $Y=33.38 X-$ 62.247 (lawsone), $Y=44.70 X-271.25$ (quercetin), $Y=$ $94.367 X-13.345$ (MNQ), and $Y=56.855 X+53.611$ (kaempferol).

HAEIBS $(10 \mathrm{mg}$ ) was dissolved in $10 \mathrm{~mL}$ methanol, passed through a $0.45 \mu \mathrm{m}$ membrane filter, and then analyzed immediately after extraction to avoid possible chemical degradation. All samples were assayed in triplicate.

\section{Results}

3.1. HAEIBS Exposure Causes Lethality in C. elegans. Lethality is a commonly used endpoint when evaluating toxicity in nematodes. To test if HAEIBS exposure is lethal to C. elegans, L1 larvae stage nematodes were treated with concentrations of HAEIBS of $0,0.1,1,5$, or $10 \mathrm{mg} / \mathrm{mL}$. As shown in Figure 1(a), treatment with $0.1 \mathrm{mg} / \mathrm{mL}$ HAEIBS caused no significant lethality in C. elegans. However, exposure to $1 \mathrm{mg} / \mathrm{mL}$ of HAEIBS moderately decreased nematode survival compared to the controls, while 5 and $10 \mathrm{mg} / \mathrm{mL}$ of HAEIBS significantly reduced survival $(p<0.01)$ by $17 \%$ and $24 \%$, respectively.

3.2. HAEIBS Inhibits C. elegans Locomotion. Nematode locomotion is neuronally controlled and includes movements, such as head thrashes and body bends that can be secondary targets of toxins. Therefore, alterations in locomotion are useful for evaluating toxicity in nematodes. It was found that exposure to a low dose of $0.1 \mathrm{mg} / \mathrm{mL}$ HAEIBS had no effect on locomotion, but higher doses of $5-10 \mathrm{mg} / \mathrm{mL}$ caused a significant decrease in both head thrashes and body bends. Specifically, there was an approximately $30 \%$ reduction in head thrashes and body bends after being treated with $10 \mathrm{mg} / \mathrm{mL}$ HAEIBS (Figures 1(b) and 1(c)). This data further validates the sensitivity of locomotion to toxins when assessing toxicity in nematodes.

\subsection{High Doses of HAEIBS Negatively Affect the Reproduc-} tion of C. elegans. I. balsamina stems may contain toxin(s) that negatively impact reproduction as folk medicine has long prohibited the use of "Tougucao," a herbal medicine containing I. balsamina, during pregnancy. Thus, the effect of HAEIBS on the reproduction of $C$. elegans was analyzed using brood size as the endpoint. When the nematodes were treated with $0.1-1 \mathrm{mg} / \mathrm{mL}$ of HAEIBS for 48 hours, there was no notable change in their brood size. However, when the concentration of HAEIBS was increased to 5 or $10 \mathrm{mg} / \mathrm{mL}$, the brood size of treated nematodes decreased. Strikingly, exposure to $10 \mathrm{mg} / \mathrm{mL}$ HAEIBS led to an approximately $25 \%$ reduction in the brood size of treated nematodes (Figure 1(d)).

3.4. Exposure to High Concentrations of HAEIBS Reduces the Lifespan of C. elegans. Next, the effect of exposure to HAEIBS on the lifespan of $C$. elegans was investigated. Lifespan is an important endpoint as it is likely reflective of any longterm effects of a specific toxin in nematodes. In this study, exposure to $10 \mathrm{mg} / \mathrm{mL}$ of HAEIBS significantly decreased the lifespan of nematodes. Specifically, the rate of survival of treated nematodes started to drop 5 days posttreatment, while almost all of the nematodes in control group were still surviving at this time. In addition, the difference in lifespan between the HAEIBS-treated and control nematodes was directly correlated with the number of days posttreatment. By the 10th day, more than $20 \%$ of the treated C. elegans had died, while more than $90 \%$ of the control nematodes were still alive. At 14 days posttreatment, the survival rate of the control group was more than double that of HAEIBS-treated nematodes. Finally, all the HAEIBS-treated C. elegans had died by 18 days posttreatment, while about $20 \%$ of the control nematodes were still alive. Therefore, this data indicates that exposure to HAEIBS significantly reduces the lifespan of $C$. elegans (Figure 1(e)).

3.5. Identification of the Chemical Components in HAEIBS. To determine which compound(s) are causing HAEIBS toxicity, the chemical components in HAEIBS were separated and tested for toxicity. First, HAEIBS components were split into acetyl acetate and light petroleum fractions according to their polarity. After assessing for toxicity, it was noted that only the acetyl acetate fraction had adverse effects on the survival, locomotion, and reproduction of $C$. elegans (unpublished data). This fraction was then further separated by HSCCC. 


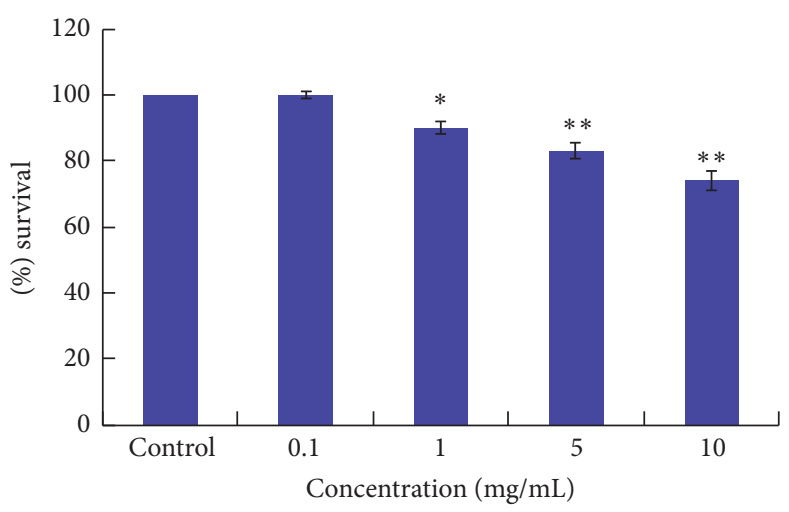

(a)

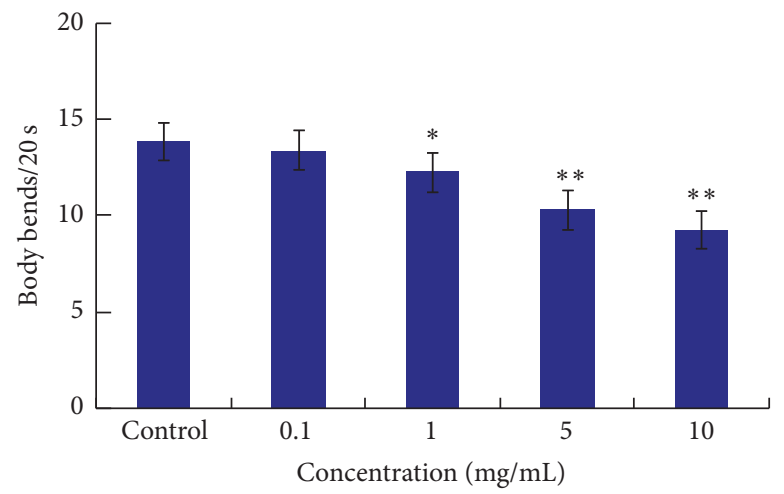

(c)

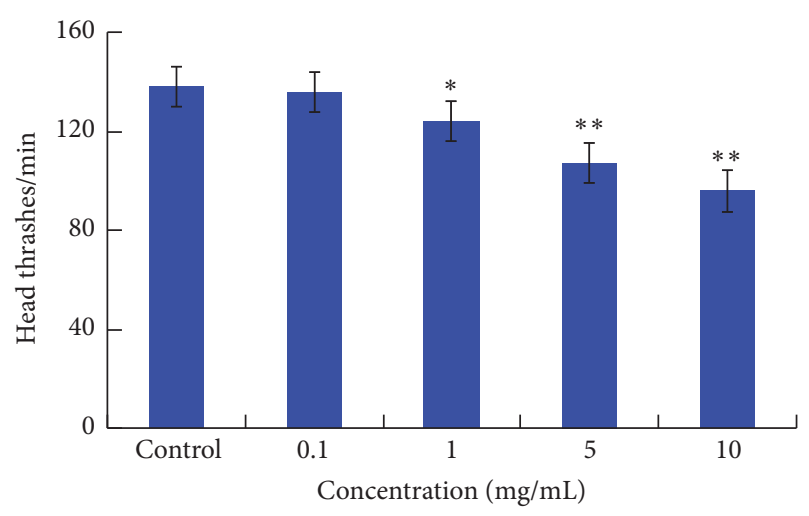

(b)

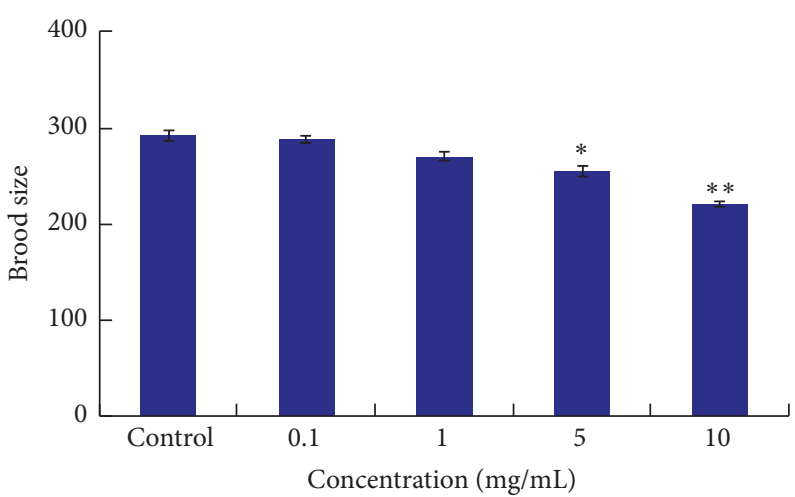

(d)

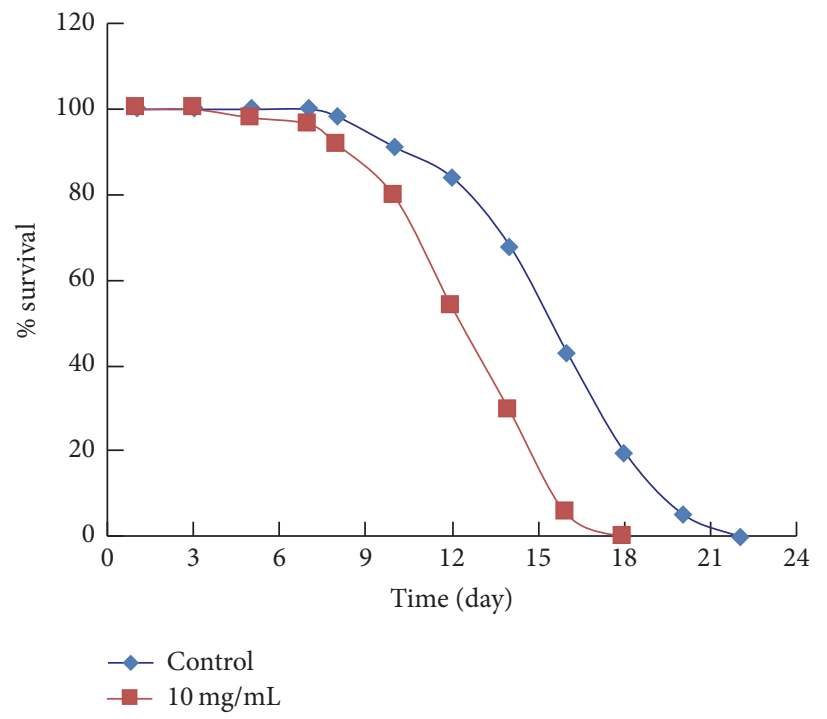

(e)

FIGURE 1: Effects of HAEIBS exposure on C. elegans. (a) The survival of L1 larvae after exposure to different concentrations of HAEIBS. $N=50$. (b) The number of nematodes displaying head thrashing 1 min postexposure to different concentrations of HAEIBS. $N=15$. (c) The number of nematodes displaying body bending within 20 seconds after HAEIBS treatment. $N=15$. (d) The number of progeny produced by nematodes treated with different concentrations of HAEIBS. $N=10$. (e) Effects of $10 \mathrm{mg} / \mathrm{mL}$ HAEIBS on nematode lifespan. $N=50$. C. elegans were exposed to HAEIBS for 48 hours spanning the L1 larvae to young adult stages. Bars represent means \pm SEM; ${ }^{*} p<0.05$; ${ }^{* *} p<0.01$. 
TABLE 1: Characterization of HAEIBS by RP-HPLC.

\begin{tabular}{lccccc}
\hline Compound & Linear range $(\mu \mathrm{g} / \mathrm{mL})$ & $t_{R}(\mathrm{~min})$ & Equation $^{\mathrm{a}}$ & Linearity $\left.^{2} R^{2}\right)$ & Content $(\mathrm{mg} / \mathrm{g}, \mathrm{mean} \pm \mathrm{SD})$ \\
\hline Lawsone & $3.25-52.00$ & $6.3 \sim 6.7$ & $Y=33.38 X-62.247$ & 0.9995 & $19.32 \pm 1.03$ \\
Quercetin & $7.00-56.00$ & $9.3 \sim 9.7$ & $Y=44.70 X-271.25$ & 0.9994 & $2.87 \pm 0.82$ \\
MNQ & $3.625-58.00$ & $11.1 \sim 11.6$ & $Y=94.367 X-13.345$ & 0.9996 & $31.15 \pm 1.26$ \\
Kaempferol & $3.625-58.00$ & $15.2 \sim 15.7$ & $Y=56.855 X+53.611$ & 0.9995 & $64.98 \pm 1.18$ \\
\hline
\end{tabular}

a $y=a x+b$, where $y$ is the area of the peak and $x$ is the concentration of the analyzed material. $n=3$ replicates per day with a total $n=9$ replicates over three separate days for each concentration.

Four major peak fractions were collected from HSCCC and further analyzed by EI-MS, as well as ${ }^{1} \mathrm{H}-\mathrm{NMR}$ and ${ }^{13} \mathrm{C}-\mathrm{NMR}$ spectra with TMS-based chemical shifts.

HSCCC peak I: yellow needle crystal, $\mathrm{C}_{10} \mathrm{H}_{6} \mathrm{O}_{3}$, m.p. 192-195 ${ }^{\circ} \mathrm{C}$, EI-MS, $m / z: 174\left(\mathrm{M}^{+}\right),{ }^{1} \mathrm{H}-\mathrm{NMR}$ (DMSO$\left.d_{6}, 500 \mathrm{MHz}\right): \delta_{\mathrm{H}}(\mathrm{ppm}): 8.00(1 \mathrm{H}, \mathrm{dd}, J=7.5$ and $1.0 \mathrm{~Hz}), 7.94(1 \mathrm{H}, \mathrm{dd}, J=7.5 \mathrm{and} 1.0 \mathrm{~Hz}), 7.84(1 \mathrm{H}$, $\mathrm{td}, J=7.45$ and $1.2 \mathrm{~Hz}), 7.80(1 \mathrm{H}, \mathrm{td}, J=7.45$ and $1.2 \mathrm{~Hz}$ ), $6.19(1 \mathrm{H}, \mathrm{s}, \mathrm{H}-3)$, and 11.67 (br.s, $2-\mathrm{OH}) .{ }^{13} \mathrm{C}-$ NMR (DMSO- $\left.d_{6}, 500 \mathrm{MHz}\right): \delta_{\mathrm{C}}(\mathrm{ppm}): 184.51(\mathrm{C}-4)$, 181.10 (C-1), 159.40 (C-2), 134.30 (C-6), 133.08 (C-7), 131.80 (C-10), 130.50 (C-9), 125.80 (C-5), 125.30 (C-8), 111.06 (C-3), which was in accordance with previous reports [6] on lawsone.

HSCCC peak II: yellow needle crystal, $\mathrm{C}_{15} \mathrm{H}_{10} \mathrm{O}_{7}$, m.p. $314-317^{\circ} \mathrm{C}$, EI-MS, $m / z: 302\left(\mathrm{M}^{+}\right),{ }^{1} \mathrm{H}-\mathrm{NMR}$ (DMSO- $\left.d_{6}, 500 \mathrm{MHz}\right): \delta_{\mathrm{H}}(\mathrm{ppm}): 7.72\left(1 \mathrm{H}, \mathrm{s}, \mathrm{H}-2^{\prime}\right)$, $6.92\left(1 \mathrm{H}, \mathrm{d}, J=8.5 \mathrm{~Hz}, \mathrm{H}-5^{\prime}\right), 7.58(1 \mathrm{H}, \mathrm{d}, J=$ $\left.8.5 \mathrm{~Hz}, \mathrm{H}-6^{\prime}\right), 6.44(1 \mathrm{H}, \mathrm{s}, \mathrm{H}-8), 6.22(1 \mathrm{H}, \mathrm{s}, \mathrm{H}-6), 12.51$ $(1 \mathrm{H}, \mathrm{s}, 5-\mathrm{OH}), 9.41\left(4 \mathrm{H}\right.$, br.s, $3-\mathrm{OH}, 7-\mathrm{OH}, 3^{\prime}-\mathrm{OH}$, $\left.4^{\prime}-\mathrm{OH}\right) .{ }^{13} \mathrm{C}-\mathrm{NMR}$ (DMSO- $\left.d_{6}, 500 \mathrm{MHz}\right): \delta_{\mathrm{C}}(\mathrm{ppm})$ : 175.80 (C-4), 163.90 (C-7), 160.70 (C-5), 156.10 (C-9), $146.80(\mathrm{C}-2), 145.01\left(\mathrm{C}-3^{\prime}\right), 115.63\left(\mathrm{C}-5^{\prime}\right), 147.71\left(\mathrm{C}-4^{\prime}\right)$, $135.70(\mathrm{C}-3), 120.00\left(\mathrm{C}-1^{\prime}\right), 115.10\left(\mathrm{C}-2^{\prime}\right), 122.00(\mathrm{C}-$ $\left.6^{\prime}\right), 103.00$ (C-10), 98.20 (C-6), 93.37 (C-8), which was in accordance with previous reports on quercetin [6].

HSCCC peak III: yellow needle crystal, $\mathrm{C}_{11} \mathrm{H}_{3} \mathrm{O}_{3}$, m.p. $183.5-186^{\circ} \mathrm{C}$, EI-MS, $m / z: 188\left(\mathrm{M}^{+}\right),{ }^{1} \mathrm{H}-\mathrm{NMR}$ $\left(\mathrm{DMSO}-d_{6}, 500 \mathrm{MHz}\right): \delta_{\mathrm{H}}(\mathrm{ppm}): 8.12(1 \mathrm{H}, \mathrm{dd}, J=$ 7.4 and $1.5 \mathrm{~Hz}), 8.08(1 \mathrm{H}, \mathrm{dd}, J=7.2$ and $1.5 \mathrm{~Hz}), 7.75$ $(1 \mathrm{H}, \mathrm{td}, J=7.4$ and $1.5 \mathrm{~Hz}), 7.71(1 \mathrm{H}, \mathrm{td}, J=7.4$ and $1.5 \mathrm{~Hz}), 6.18(1 \mathrm{H}, \mathrm{s}, \mathrm{H}-3)$, and $3.91(3 \mathrm{H}, \mathrm{s}) .{ }^{13} \mathrm{C}-\mathrm{NMR}$ (DMSO- $\left.d_{6}, 500 \mathrm{MHz}\right): \delta_{\mathrm{C}}(\mathrm{ppm}): 184.70(\mathrm{C}-4), 180.00$ (C-1), 160.40 (C-2), 134.20 (C-6), 133.20 (C-7), 132.00 (C-10), 131.00 (C-9), 126.60 (C-5), 126.10 (C-8), 109.80 (C-3), and 56.3 (C-11), which was in accordance with previous reports on 2-methoxy-1,4-naphthoquinone (MNQ) [4].

HSCCC peak IV: yellow needle crystal, $\mathrm{C}_{15} \mathrm{H}_{10} \mathrm{O}_{6}$, m.p. $276-278^{\circ} \mathrm{C}$, EI-MS, $m / z$ : $286\left(\mathrm{M}^{+}\right),{ }^{1} \mathrm{H}-\mathrm{NMR}$ $\left(\mathrm{DMSO}-d_{6}, 500 \mathrm{MHz}\right): \delta_{\mathrm{H}}(\mathrm{ppm}): 6.45(1 \mathrm{H}, \mathrm{d}, J=$ $1.65 \mathrm{~Hz}, \mathrm{H}-8), 6.21(1 \mathrm{H}, \mathrm{d}, J=1.65 \mathrm{~Hz}, \mathrm{H}-6), 8.06$ $\left(2 \mathrm{H}, \mathrm{d}, J=8.8 \mathrm{~Hz}, \mathrm{H}-2^{\prime}, 6^{\prime}\right), 6.94(2 \mathrm{H}, \mathrm{d}, J=8.8 \mathrm{~Hz}$, H-3' $\left.{ }^{\prime} 5^{\prime}\right), 12.49$ (1H, s, 5-OH), 10.77 (br.s, 7-OH), 10.09 (br.s, $\left.4^{\prime}-\mathrm{OH}\right), 9.36$ (br.s, 3-OH). ${ }^{13} \mathrm{C}-\mathrm{NMR}$ (DMSO$\left.d_{6}, 500 \mathrm{MHz}\right): \delta_{\mathrm{C}}(\mathrm{ppm}): 146.80(\mathrm{C}-2), 135.60(\mathrm{C}-3)$,

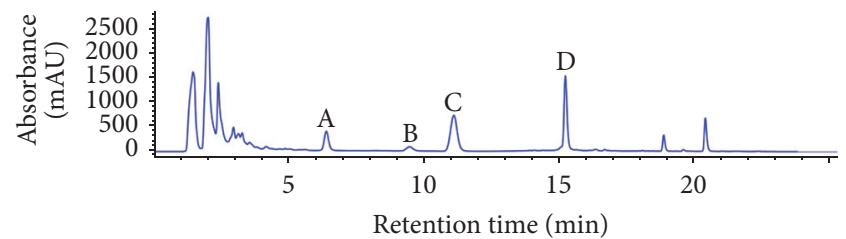

Figure 2: Characterization of HAEIBS by RP-HPLC $(\lambda=280 \mathrm{~nm})$. A: lawsone, B: quercetin, C: MNQ, and D: kaempferol.

175.80 (C-4), 160.70 (C-5), 98.10 (C-6), 163.80 (C-7), 93.40 (C-8), 156.10 (C-9), 103.00 (C-10), 121.60 (C-1'), $129.40\left(\mathrm{C}-2^{\prime}, 6^{\prime}\right), 115.40\left(\mathrm{C}-3^{\prime}, 5^{\prime}\right)$, and $159.10\left(\mathrm{C}-4^{\prime}\right)$, which was in accordance with previous reports on kaempferol [35].

Using reverse-phase high performance liquid chromatography (RP-HPLC), the abundances of lawsone, quercetin, MNQ, and kaempferol were measured in HAEIBS (Figure 2) and were $19.32,2.87,31.15$, and $64.98 \mathrm{mg} / \mathrm{g}$, respectively (Table 1).

3.6. Lawsone and MNQ Are the Primary Toxins in HAEIBS. Of the 4 compounds isolated from HAEIBS, quercetin and kaempferol on nematodes have also been examined by our group. These compounds can extend the lifespan and enhance locomotion of C. elegans at a concentration of $60 \mu \mathrm{g} / \mathrm{mL}$. These results are consistent with previous reports in $C$. elegans [36-39] and, thus, are unlikely to mediate the HAEIBS toxicity observed in this study. Therefore, lawsone and MNQ were pursued as the potential cause(s) of HAEIBS toxicity and the toxicity of different concentrations of these two pure compounds was analyzed in C. elegans.

As shown in Figure 3(a), exposure to $0.1 \mathrm{mg} / \mathrm{mL}$ of lawsone only moderately decreased the survival of nematode compared to the control. However, there was about a 30\% decrease in survival for nematodes treated with $0.2 \mathrm{mg} / \mathrm{mL}$ lawsone. When treated with $0.5 \mathrm{mg} / \mathrm{mL}$ of lawsone, more than $90 \%$ of nematodes died, indicating that lawsone is very toxic to $C$. elegans. Although there was no significant lethality observed when nematodes were treated with 0.1 or $0.2 \mathrm{mg} / \mathrm{mL}$ of $\mathrm{MNQ}$, exposure to $0.3-0.5 \mathrm{mg} / \mathrm{mL}$ of MNQ caused a moderate decrease in nematode survival compared to the controls.

Exposure to a low dose of $0.1 \mathrm{mg} / \mathrm{mL}$ of lawsone moderately affected nematode locomotion, while higher doses of 

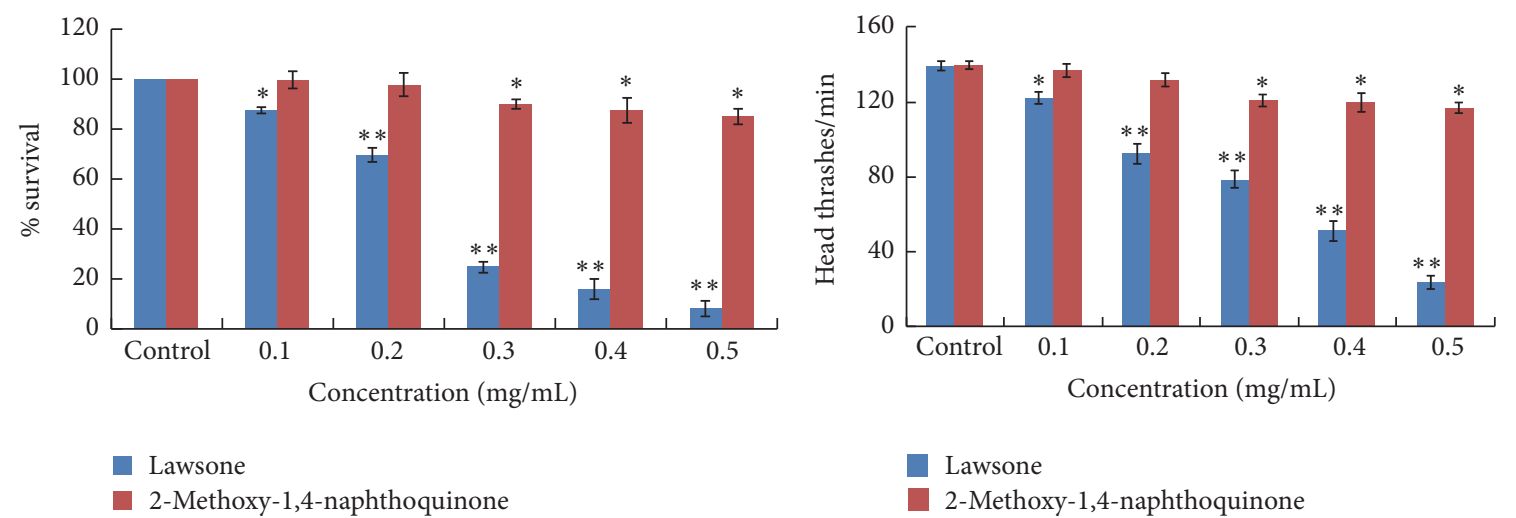

(a)

(b)

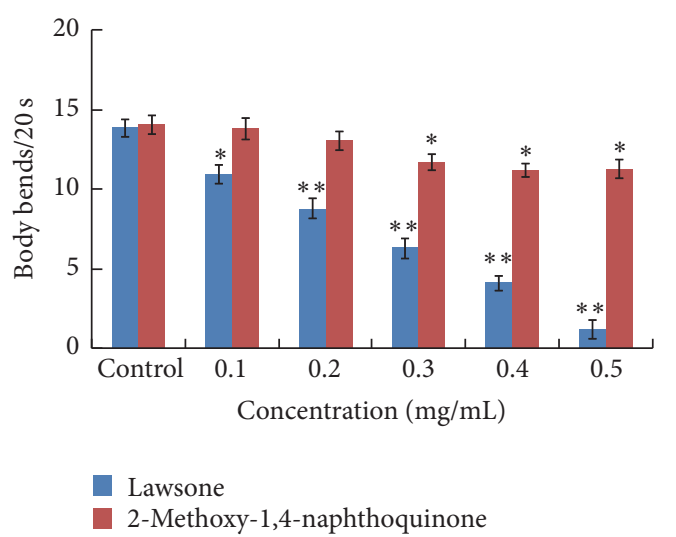

(c)

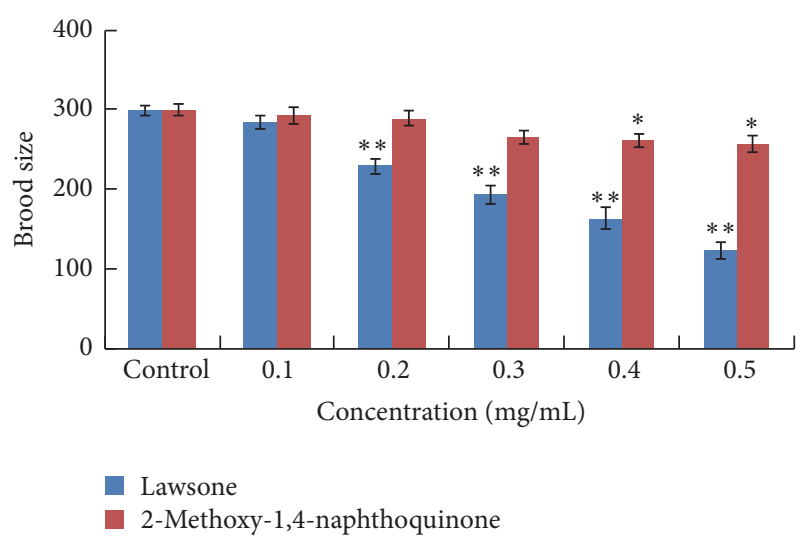

(d)

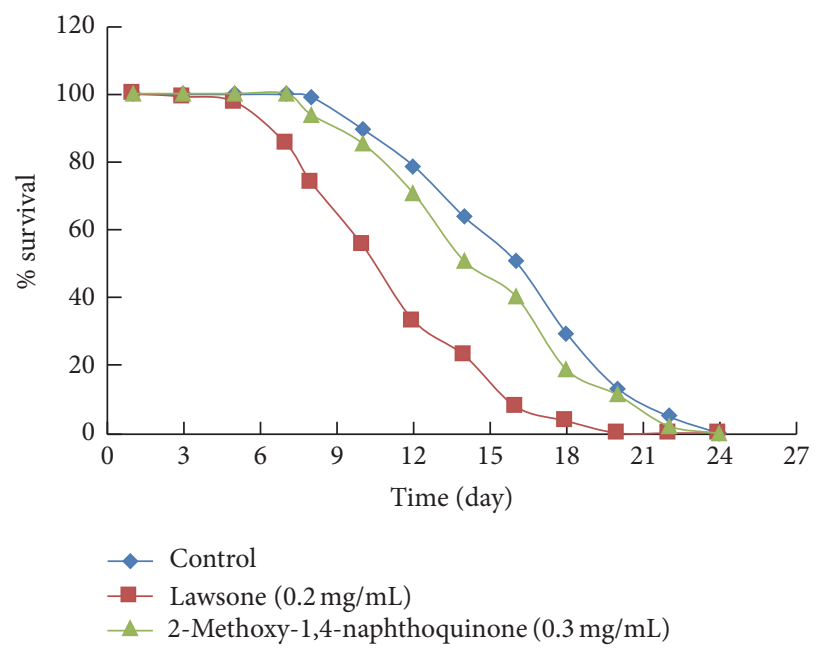

(e)

Figure 3: Effects of exposure of lawsone and MNQ on C. elegans. (a) The survival L1 larvae after exposure to different concentrations of lawsone or MNQ. $N=50$. (b) The number of nematodes displaying head thrashing within 1 minute after exposure to different concentrations of lawsone or MNQ. $N=15$. (c) The number of nematodes displaying body bending within 20 seconds after lawsone or MNQ treatment. $N=15$. (d) The number of progeny produced by nematodes treated with different concentrations of lawsone or MNQ. $N=10$. (e) Effects of lawsone and MNQ nematode lifespan. $N=50$. C. elegans were exposed to lawsone or MNQ for 48 hours spanning the L1 larvae to young adult stages. Bars represent means \pm SEM; ${ }^{*} p<0.05 ;{ }^{* *} p<0.01$. 
$0.2-0.5 \mathrm{mg} / \mathrm{mL}$ caused significant decreases in both nematode head thrashing and body bending. There was about a $33 \%$ reduction in the amount of head thrashes and body bends after being treated with $0.2 \mathrm{mg} / \mathrm{mL}$ lawsone (Figures $3(\mathrm{~b})$ and $3(\mathrm{c}))$. Exposure to a low dose $(0.1-0.2 \mathrm{mg} / \mathrm{mL})$ of MNQ did not affect nematode locomotion, but higher doses $(0.3-0.5 \mathrm{mg} / \mathrm{mL})$ led to slight decreases in both nematode head thrashing and body bending (Figures $3(\mathrm{~b})$ and $3(\mathrm{c})$ ).

Lawsone also displayed reproductive toxicity in C. elegans. Although a low dose of $0.1 \mathrm{mg} / \mathrm{mL}$ had no significant effect on nematode brood size, concentrations of $0.2 \mathrm{mg} / \mathrm{mL}$ or higher of lawsone lead to significant decreases in brood size compared to untreated nematodes. Specifically, treatment with 0.2 and $0.5 \mathrm{mg} / \mathrm{mL}$ lawsone caused $24 \%$ and $50 \%$ reductions in brood size, respectively (Figure 3(d)).

Although MNQ did not notably reduce the nematode lifespan at a $0.3 \mathrm{mg} / \mathrm{mL}$ concentration, the lifespan of nematode was greatly reduced after treatment with $0.2 \mathrm{mg} / \mathrm{mL}$ lawsone. The survival of lawsone-treated nematodes started to drop 6 days after treatment and about 30\% of lawsonetreated nematodes died by 8 days posttreatment. At 10 days posttreatment, more than half of the treated $C$. elegans had died compared to only $10 \%$ of the control nematodes (Figure 3(e)). By 18 days posttreatment, all lawsone-treated $C$. elegans had died compared to the control nematodes, where $30 \%$ were still alive. Therefore, our data indicates that lawsone significantly reduces the lifespan of $C$. elegans and is more toxic than MNQ.

\section{Discussion}

C. elegans are invertebrates well suited for use as an animal model due to their short lifecycle, fast reproduction, and wellcharacterized genome [17]. This model has been successfully used in the assessment of toxicity of heavy metals [40-44], environmental pollutants $[45,46]$, and specific components of plant extracts $[21,23]$. As a whole, these previous studies have resulted in the acceptance of the use of $C$. elegans as a bioindicator in toxicity studies [23, 45, 47, 48]. As further validation, toxicological studies conducted in C. elegans have yielded similar results to parallel studies in mammalian models [28]. In our study, C. elegans was used to evaluate toxicity of plant extracts and compounds isolated from HAEIBS. Our data further supports the use of $C$. elegans as a rapid and systemic assay system by which to assess toxicity of specific Chinese medicines or plant extracts.

I. balsamina stems have long been used in TCM for the treatment of a range of diseases and ailments [7, 13, 14, 4957]. However, there have been very few studies regarding its potential toxicity $[16,58-63]$. Therefore, this present study was designed to comprehensively examine I. balsamina stems toxicity and identify any potential toxins. In this work, it was demonstrated that exposure to HAEIBS affected the survival, locomotion, reproduction, and lifespan of C. elegans, indicating that $I$. balsamina stems do display toxicity in animals.

In addition, 4 major compounds were isolated from HAEIBS and identified using HSCCC and reverse-phase
HPLC, and lawsone and MNQ were found to be the major mediators of HAEIBS toxicity in C. elegans. Our data indicates that lawsone at a concentration as low as $0.2 \mathrm{mg} / \mathrm{mL}$ displayed significant toxicity in C. elegans based on reductions of $30.5 \%$ reduction in survival rate, $33.63 \%$ in head thrashes per minute, $36.46 \%$ in body bends per 20 seconds, and $24 \%$ of brood size (Figure 3). Interestingly, similar adverse effects were also observed when $C$. elegans were treated with $10 \mathrm{mg} / \mathrm{mL}$ of HAEIBS (Figure 1). Based on the abundance of these compounds in HAEIBS, it was calculated that 1 gram of HAEIBS contains $19.32 \mathrm{mg}$ of lawsone. Therefore, $0.2 \mathrm{mg}$ of pure lawsone is similar to the amount found in $10 \mathrm{mg}$ HAEIBS, clearly suggesting that lawsone is the major toxin in I. balsamina. Compared to lawsone, MNQ seemed to be much less toxic as it had no notable toxicity, even at a concentration of $0.5 \mathrm{mg} / \mathrm{mL}$, which is more than 30 times higher than the amount contained in HAEIBS.

The common protocol of preparing most Chinese herb medicine is to decoct herbal material with water for certain time. Then the aqueous part will contain most of the rapeutically active components for treatment. We tried to decoct $I$. balsamina stems powder with boiling water at the beginning. However, due to the poor efficiency of extraction, we could not collect enough samples for further analytical analysis. That was the reason we chose to use hydroalcoholic (EtOH $55 \%$ ) to do the extraction. Figure 4 shows the result of HPLC analysis on compounds extracted by either boiling water (Figure 4(a)) or hydroalcoholic (EtOH 55\%) (Figure 4(b)) from equal amount of I. balsamina stems powder. Clearly, there are huge differences in terms of the abundance of compounds with similar retention time between two different methods. However, peaks with the same retention time from two extractions also have very similar absorption spectrum, suggesting that they are the same compounds. For example, Lawson, the peak at 6.4 minutes in hydroalcoholic $(\mathrm{EtOH}$ $55 \%$ ) extracts, has a corresponding peak with similar absorption spectrum in boiling water extracts, although with much lower signal. Same is true for MNQ. This indicates that the potential toxicants we found in HAEIBS can also be extracted by boiling water. We measured concentration of those four compounds identified from HAEIBS in boiling water extracts of I. balsamina stems. Their concentrations are 3.17, 1.73, 0.85 , and $1.17 \mathrm{mg} / \mathrm{g}$, respectively. Overall, hydroalcoholic (EtOH 55\%) extraction enabled better yield of compounds comparing to boiling water but with much less efficiency. We also measured abundance of lawsone and MNQ in daily dose of "Tougucao" (9-15 g, boiled in water), and 32.4-54 mg of lawsone were detected (unpublished data). Considering $0.2 \mathrm{mg} / \mathrm{mL}$ of lawsone had caused toxicity in C. elegans and the extreme sensitivity of the human embryo, prohibiting prescribing pregnant women with "Tougucao" is a sound decision.

Likely due to differences in abundance or solubility in the HSCCC solvents, only 6 compounds were isolated from the acetyl acetate fraction of HAEIBS. Four of these were identified successfully (Figure 2). However, the lack of purity and low yield prevented a determination of their structures. Because these 2 compounds did not have any adverse effects on nematodes (unpublished data), we did not 


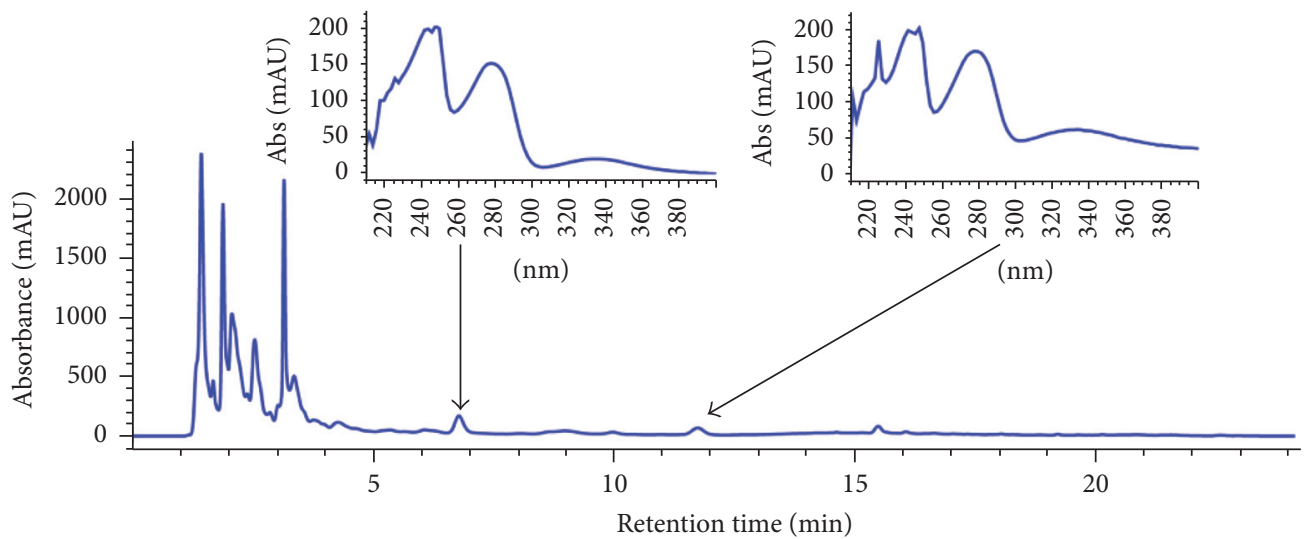

(a)

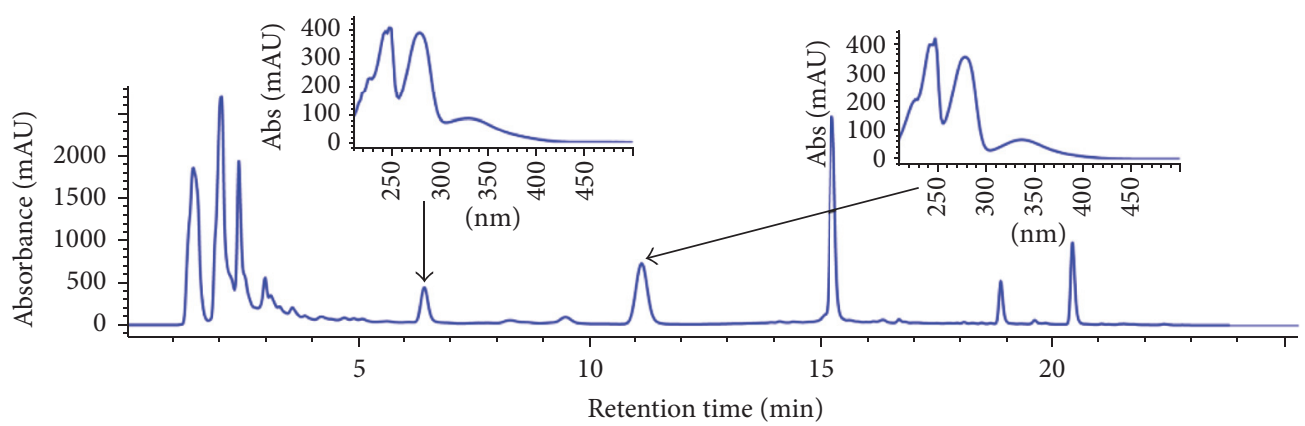

(b)

FIGURE 4: HPLC-DAD of (a) boiling water extracts of I. balsamina stems; and (b) hydroalcoholic (EtOH 55\%) extracts of I. balsamina stems $(\lambda=280 \mathrm{~nm})$. The insets are absorption spectrum of peaks which arrows point to.

study them further. Comparison of the levels of toxicity of raw HAEIBS and pure lawsone and MNQ in nematodes clearly demonstrated that lawsone and MNQ are the primary toxins in HAEIBS. Therefore, even if there are other compounds that were not successfully isolated or identified from HAEIBS via HSCCC, they are unlikely to be major HAEIBS toxins.

\section{Conclusions}

This research studied the potential toxic effects of HAEIBS in vivo and identified lawsone and MNQ as toxins within HAEIBS. Furthermore, it was found that lawsone is the primary toxin, as it is more severely toxic than MNQ. In the future, certain strategies, such as modifying the processing procedure, should be considered to reduce the possible adverse effects of $I$. balsamina stems.

\section{Competing Interests}

The authors declare that they have no competing interests.

\section{Authors' Contributions}

Hong-Fang Jiang and Zi-Heng Zhuang contributed equally to this work.

\section{Acknowledgments}

This work was supported by the national "Twelfth Five Year Plan" key project of the Science and Technology Support Program [Grant no. 2012BAD36B01].

\section{References}

[1] Jiangsu New Medical College, The Dictionary of Chinese Herbal Medicines, Shanghai Science and Technology Publisher, Shanghai, China, 1986.

[2] S. Clevenger, "The flavonols of Impatiens balsamina L," Archives of Biochemistry and Biophysics, vol. 76, no. 1, pp. 131-138, 1958.

[3] C.-W. Glennie and B.-A. Bohm, "The isolation of 2-Hydroxy1,4-Naphthoquinone from Impatiens Balsamina L. (Balsaminaceae)," Canadian Journal of Biochemistry, vol. 43, no. 2, pp. 293-295, 1965.

[4] N. Mori, K. Toume, M. A. Arai, T. Koyano, T. Kowithayakorn, and M. Ishibashi, "2-methoxy-1,4-naphthoquinone isolated from Impatiens balsamina in a screening program for activity to inhibit Wnt signaling," Journal of Natural Medicines, vol. 65, no. 1, pp. 234-236, 2011.

[5] C. D. Miles and C. W. Hagen, "2-methoxy-1,4-naphthoquinone isolated from Impatiens balsamina in a screening program for activity to inhibit Wnt signaling," Plant Physiology, vol. 43, no. 9, pp. 1347-1354, 1968.

[6] H. Oku and K. Ishiguro, "Screening method for PAF antagonist substances: on the phenolic compounds from Impatients 
balsamina L.," Phytotherapy Research, vol. 13, no. 6, pp. 521-525, 1999.

[7] S.-N. Kang, Y.-M. Goo, M.-R. Yang et al., "Antioxidant and antimicrobial activities of ethanol extract from the stem and leaf of Impatiens balsamina L. (balsaminaceae) at different harvest times," Molecules, vol. 18, no. 6, pp. 6356-6365, 2013.

[8] B.-L. Su, R. Zeng, J.-Y. Chen, C.-Y. Chen, J.-H. Guo, and C.G. Huang, "Antioxidant and antimicrobial properties of various solvent extracts from Impatiens balsamina L. stems," Journal of Food Science, vol. 77, no. 6, pp. C614-C619, 2012.

[9] Z.-S. Ding, F.-S. Jiang, N.-P. Chen, G.-Y. Lv, and C.-G. Zhu, "Isolation and identification of an anti-tumor component from leaves of Impatiens balsamina," Molecules, vol. 13, no. 2, pp. 220$229,2008$.

[10] Y.-C. Wang and Y.-H. Lin, "Anti-gastric adenocarcinoma activity of 2-Methoxy-1,4-naphthoquinone, an anti-Helicobacter pylori compound from Impatiens balsamina L.," Fitoterapia, vol. 83, no. 8, pp. 1336-1344, 2012.

[11] K. Ishiguro, Y. Ohira, and H. Oku, "Preventive effects of impatiens balsamina on the hen egg-white lysozyme (HEL)induced decrease in blood flow," Biological and Pharmaceutical Bulletin, vol. 25, no. 4, pp. 505-508, 2002.

[12] G. S. Thakur, M. Bag, B. S. Sanodiya et al., "Momordica balsamina: a medicinal and neutraceutical plant for health care management," Current Pharmaceutical Biotechnology, vol. 10, no. 7, pp. 667-682, 2009.

[13] H. Oku and K. Ishiguro, "Antipruritic and antidermatitic effect of extract and compounds of Impatiens balsamina L. in Atopic dermatitis model NC mice," Phytotherapy Research, vol. 15, no. 6, pp. 506-510, 2001.

[14] M. Z. Imam, N. Nahar, S. Akter, and M. S. Rana, "Antinociceptive activity of methanol extract of flowers of Impatiens balsamina," Journal of Ethnopharmacology, vol. 142, no. 3, pp. 804-810, 2012.

[15] X. Fan, H. Schäfer, J. Reichling, and M. Wink, "Bactericidal properties of the antimicrobial peptide Ib-AMP4 from Impatiens balsamina produced as a recombinant fusion-protein in Escherichia coli," Biotechnology Journal, vol. 8, no. 10, pp. 12131220, 2013.

[16] H. Pei, J. Lei, and S.-H. Qian, "A new cytotoxic dinaphthofuran7,12-dione derivatives from the seeds of Impatiens balsamina L.," Journal of Chinese Medicinal Materials, vol. 35, no. 3, pp. 407410, 2012.

[17] M. C. K. Leung, P. L. Williams, A. Benedetto et al., "Caenorhabditis elegans: an emerging model in biomedical and environmental toxicology," Toxicological Sciences, vol. 106, no. 1, pp. 528, 2008.

[18] Y.-L. Zhao and D.-Y. Wang, "Formation and regulation of adaptive response in nematode Caenorhabditis elegans," Oxidative Medicine and Cellular Longevity, vol. 2012, Article ID 564093, 6 pages, 2012.

[19] V. Dostal, C. M. Roberts, and C. D. Link, "Genetic mechanisms of coffee extract protection in a Caenorhabditis elegans model of $\beta$-amyloid peptide toxicity," Genetics, vol. 186, no. 3, pp. 857866, 2010.

[20] W. Zhang, T. Lv, M. Li et al., "Beneficial effects of wheat gluten hydrolysate to extend lifespan and induce stress resistance in nematode Caenorhabditis elegans," PLOS ONE, vol. 8, no. 9, Article ID e74553, 2013.
[21] D. Mukai, N. Matsuda, Y. Yoshioka, M. Sato, and T. Yamasaki, "Potential anthelmintics: polyphenols from the tea plant Camellia sinensis L. are lethally toxic to Caenorhabditis elegans," Journal of Natural Medicines, vol. 62, no. 2, pp. 155-159, 2008.

[22] J. S. Sangha, X. Sun, O. S. D. Wally et al., "Liuwei Dihuang (LWDH), a traditional Chinese medicinal formula, protects against $\beta$-amyloid toxicity in transgenic Caenorhabditis elegans," PLoS ONE, vol. 7, no. 8, Article ID e43990, 2012.

[23] Y. Qiao, Y. Zhao, Q. Wu et al., "Full toxicity assessment of genkwa flos and the underlying mechanism in nematode Caenorhabditis elegans," PLOS ONE, vol. 9, no. 3, Article ID e91825, 2014.

[24] C. A. Antunes, L. Clark, M.-T. Wanuske et al., "Caenorhabditis elegans star formation and negative chemotaxis induced by infection with corynebacteria," Microbiology, vol. 162, no. 1, pp. 84-93, 2016.

[25] R. Niwayama and A. Kimura, "A cellular funicular: a hydrodynamic coupling between the anterior- and posterior-directed cytoplasmic flows," Worm, vol. 1, no. 1, pp. 72-76, 2012.

[26] M.-S. Gami, W.-B. Iser, K.-B. Hanselman, and C.-A. Wolkow, "Activated AKT/PKB signaling in C. elegans uncouples temporally distinct outputs of DAF-2/insulin-like signaling," $B M C$ Developmental Biology, vol. 6, article 45, 2006.

[27] T. Kaletta and M. O. Hengartner, "Finding function in novel targets: C. elegans as a model organism," Nature Reviews Drug Discovery, vol. 5, no. 5, pp. 387-399, 2006.

[28] R. L. Sprando, N. Olejnik, H. N. Cinar, and M. Ferguson, "A method to rank order water soluble compounds according to their toxicity using caenorhabditis elegans, a complex object parametric analyzer and sorter, and axenic liquid media," Food and Chemical Toxicology, vol. 47, no. 4, pp. 722-728, 2009.

[29] S. Brenner, "The genetics of Caenorhabditis elegans," Genetics, vol. 77, no. 1, pp. 71-94, 1974.

[30] G. L. Anderson, W. A. Boyd, and P. L. Williams, "Assessment of sublethal endpoints for toxicity testing with the nematode Caenorhabditis elegans," Environmental Toxicology and Chemistry, vol. 20, no. 4, pp. 833-838, 2001.

[31] D. Wang and X. Xing, "Assessment of locomotion behavioral defects induced by acute toxicity from heavy metal exposure in nematode Caenorhabditis elegans," Journal of Environmental Sciences, vol. 20, no. 9, pp. 1132-1137, 2008.

[32] K. Schouest, A. Zitova, C. Spillane, and D. B. Papkovsky, “Toxicological assessment of chemicals using Caenorhabditis elegans and optical oxygen respirometry," Environmental Toxicology and Chemistry, vol. 28, no. 4, pp. 791-799, 2009.

[33] L. Shen, Y. Hu, T. Cai, X. Lin, and D. Wang, "Regulation of longevity by genes required for the functions of AIY interneuron in nematode Caenorhabditis elegans," Mechanisms of Ageing and Development, vol. 131, no. 11-12, pp. 732-738, 2010.

[34] L.-L. Shen, M. Du, X.-F. Lin, T. Cai, and D.-Y. Wang, "Genes required for the functions of olfactory AWA neuron regulate the longevity of Caenorhabditis elegans in an insulin/IGF signalingdependent fashion," Neuroscience Bulletin, vol. 26, no. 2, pp. 91103,2010

[35] L. Hua, Z. Peng, L. S. Chia, N. K. Goh, and S. N. Tan, "Separation of kaempferols in Impatiens balsamina flowers by capillary electrophoresis with electrochemical detection," Journal of Chromatography A, vol. 909, no. 2, pp. 297-303, 2001.

[36] A. Kampkötter, C. G. Nkwonkam, R. F. Zurawski et al., "Investigations of protective effects of the flavonoids quercetin and rutin on stress resistance in the model organism Caenorhabditis elegans," Toxicology, vol. 234, no. 1-2, pp. 113-123, 2007. 
[37] A. Kampkötter, C. Timpel, R. F. Zurawski et al., "Increase of stress resistance and lifespan of Caenorhabditis elegans by quercetin," Comparative Biochemistry and Physiology-B Biochemistry and Molecular Biology, vol. 149, no. 2, pp. 314-323, 2008.

[38] E. Fitzenberger, D. J. Deusing, C. Marx, M. Boll, K. Lüersen, and U. Wenzel, "The polyphenol quercetin protects the mev1 mutant of Caenorhabditis elegans from glucose-induced reduction of survival under heat-stress depending on SIR-2.1, DAF-12, and proteasomal activity," Molecular Nutrition and Food Research, vol. 58, no. 5, pp. 984-994, 2014.

[39] A. Kampkötter, C. Gombitang Nkwonkam, R. F. Zurawski et al., "Effects of the flavonoids kaempferol and fisetin on thermotolerance, oxidative stress and FoxO transcription factor DAF16 in the model organism Caenorhabditis elegans," Archives of Toxicology, vol. 81, no. 12, pp. 849-858, 2007.

[40] X. Xing, M. Du, Y. Zhang, and D. Wang, "Adverse effects of metal exposure on chemotaxis towards water-soluble attractants regulated mainly by ASE sensory neuron in nematode Caenorhabditis Elegans," Journal of Environmental Sciences, vol. 21, no. 12, pp. 1684-1694, 2009.

[41] X. Xing, Q. Rui, and D. Wang, "Lethality toxicities induced by metal exposure during development in nematode caenorhabditis elegans," Bulletin of Environmental Contamination and Toxicology, vol. 83, no. 4, pp. 530-536, 2009.

[42] D. Wang and X. Xing, "Pre-treatment with mild metal exposure suppresses the neurotoxicity on locomotion behavior induced by the subsequent severe metal exposure in Caenorhabditis elegans," Environmental Toxicology and Pharmacology, vol. 28, no. 3, pp. 459-464, 2009.

[43] S. Zeitoun-Ghandour, J. M. Charnock, M. E. Hodson, O. I. Leszczyszyn, C. A. Blindauer, and S. R. Stürzenbaum, "The two Caenorhabditis elegans metallothioneins (CeMT-1 and CeMT2) discriminate between essential zinc and toxic cadmium," The FEBS Journal, vol. 277, no. 11, pp. 2531-2542, 2010.

[44] H. Zhang, X. He, W. Bai et al., "Ecotoxicological assessment of lanthanum with Caenorhabditis elegans in liquid medium," Metallomics, vol. 2, no. 12, pp. 806-810, 2010.

[45] Y. Li, H. Ye, M. Du et al., "Induction of chemotaxis to sodium chloride and diacetyl and thermotaxis defects by microcystinLR exposure in nematode Caenorhabditis elegans," Journal of Environmental Sciences, vol. 21, no. 7, pp. 971-979, 2009.

[46] W. A. Boyd, M. V. Smith, G. E. Kissling et al., "Application of a mathematical model to describe the effects of chlorpyrifos on Caenorhabditis elegans development," PLoS ONE, vol. 4, no. 9, Article ID e7024, 2009.

[47] M. H. A. Z. Mutwakil, J. P. Reader, D. M. Holdich et al., "Use of stress-inducible transgenic nematodes as biomarkers of heavy metal pollution in water samples from an English river system," Archives of Environmental Contamination and Toxicology, vol. 32, no. 2, pp. 146-153, 1997.

[48] S. Wabnig, J. F. Liewald, S.-C. Yu, and A. Gottschalk, "Highthroughput all-optical analysis of synaptic transmission and synaptic vesicle recycling in Caenorhabditis elegans," PLoS ONE, vol. 10, no. 8, Article ID e0135584, 2015.

[49] Y.-C. Wang, D.-C. Wu, J.-J. Liao, C.-H. Wu, W.-Y. Li, and B.C. Weng, "In vitro activity of Impatiens balsamina L. against multiple antibiotic-resistant Helicobacter pylori," The American Journal of Chinese Medicine, vol. 37, no. 4, pp. 713-722, 2009.

[50] A. M. Madureira, C. Ramalhete, S. Mulhovo, A. Duarte, and M.J. U. Ferreira, "Antibacterial activity of some African medicinal plants used traditionally against infectious diseases," Pharmaceutical Biology, vol. 50, no. 4, pp. 481-489, 2012.

[51] S. Semenya, M. Potgieter, and L. Erasmus, "Ethnobotanical survey of medicinal plants used by Bapedi healers to treat diabetes mellitus in the Limpopo Province, South Africa," Journal of Ethnopharmacology, vol. 141, no. 1, pp. 440-445, 2012.

[52] S. E. Atawodi, D. A. Ameh, S. Ibrahim et al., "Indigenous knowledge system for treatment of trypanosomiasis in Kaduna State of Nigeria," Journal of Ethnopharmacology, vol. 79, no. 2, pp. 279-282, 2002.

[53] G. J. Kapadia, G. S. Rao, R. Sridhar et al., "Chemoprevention of skin cancer: effect of Lawsonia inermis L. (henna) leaf powder and its pigment artifact, lawsone in the epstein- barr virus early antigen activation assay and in two-stage mouse skin carcinogenesis models," Anti-Cancer Agents in Medicinal Chemistry, vol. 13, no. 10, pp. 1500-1507, 2013.

[54] N. Diarra, C. van't Klooster, A. Togola, D. Diallo, M. Willcox, and J. D. Jong, "Ethnobotanical study of plants used against malaria in Sélingué subdistrict, Mali," Journal of Ethnopharmacology, vol. 166, pp. 352-360, 2015.

[55] A. B. Hsouna, S. Mongi, G. Culioli et al., "Protective effects of ethyl acetate fraction of Lawsonia inermis fruits extract against carbon tetrachloride-induced oxidative damage in rat liver," Toxicology and Industrial Health, vol. 32, no. 4, pp. 694-706, 2013.

[56] M. S. Arayne, N. Sultana, A. Z. Mirza, M. H. Zuberi, and F. A. Siddiqui, "In vitro hypoglycemic activity of methanolic extract of some indigenous plants," Pakistan Journal of Pharmaceutical Sciences, vol. 20, no. 4, pp. 268-273, 2007.

[57] R. Badoni Semwal, D. K. Semwal, S. Combrinck, C. CartwrightJones, and A. Viljoen, "Lawsonia inermis L. (henna): ethnobotanical, phytochemical and pharmacological aspects," Journal of Ethnopharmacology, vol. 155, no. 1, pp. 80-103, 2014.

[58] L. T. Ling, A. K. Radhakrishnan, T. Subramaniam, H. M. Cheng, and U. D. Palanisamy, "Assessment of antioxidant capacity and cytotoxicity of selected Malaysian plants," Molecules, vol. 15, no. 4, pp. 2139-2151, 2010.

[59] Q. Li, W. Gao, J. Cao et al., "New cytotoxic compounds from flowers of Lawsonia inermis L.," Fitoterapia, vol. 94, pp. 148-154, 2014.

[60] M. Kumar, P. Kaur, S. Kumar, and S. Kaur, "Antiproliferative and apoptosis inducing effects of non-polar fractions from lawsonia inermis L. in cervical (HeLa) cancer cells," Physiology and Molecular Biology of Plants, vol. 21, no. 2, pp. 249-260, 2015.

[61] M. van de Venter, S. Roux, L. C. Bungu et al., "Antidiabetic screening and scoring of 11 plants traditionally used in South Africa," Journal of Ethnopharmacology, vol. 119, no. 1, pp. 81-86, 2008.

[62] I. Kaur, M. Puri, Z. Ahmed, F. P. Blanchet, B. Mangeat, and V. Piguet, "Inhibition of HIV-1 replication by balsamin, a ribosome inactivating protein of Momordica balsamina," PLoS ONE, vol. 8, no. 9, Article ID e73780, 2013.

[63] J.-A. Shin, M. H. Ryu, K.-H. Kwon, B. Choi, and S.-D. Cho, "Down-regulation of Akt by methanol extracts of Impatiens balsamina L. promotes apoptosis in human oral squamous cell carcinoma cell lines," Journal of Oral Pathology \& Medicine, vol. 44, no. 6, pp. 420-428, 2015. 


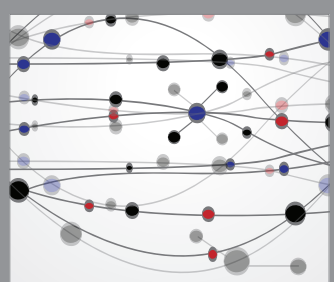

The Scientific World Journal
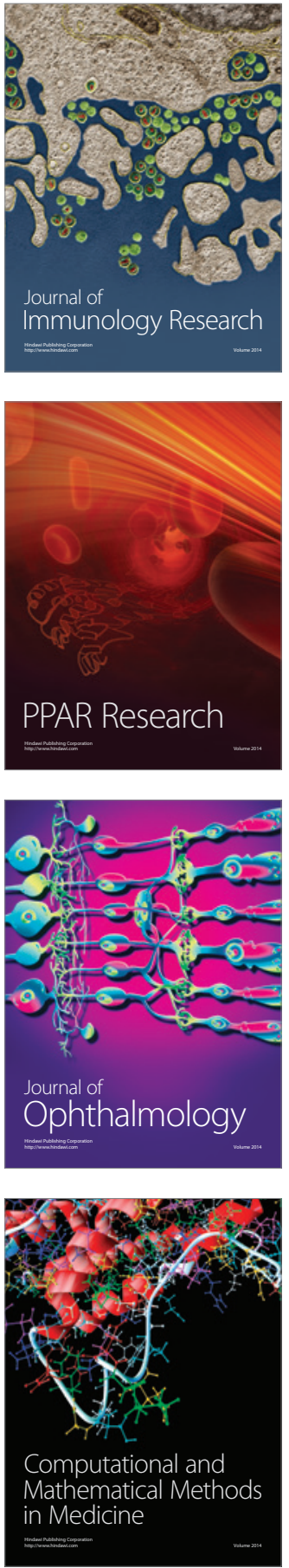

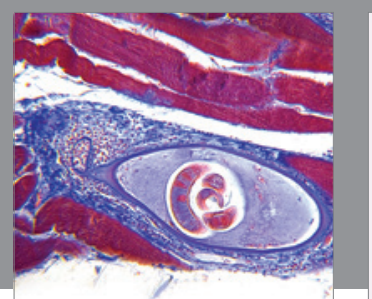

Gastroenterology Research and Practice
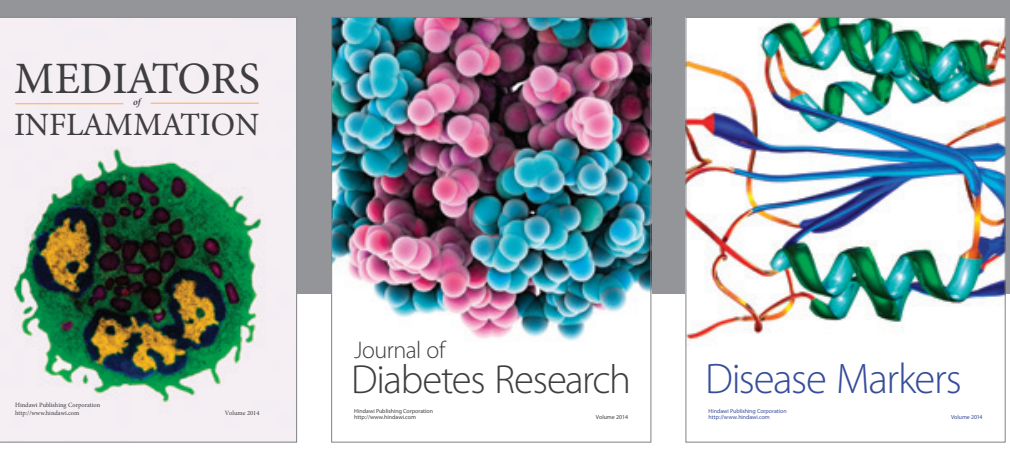

Disease Markers

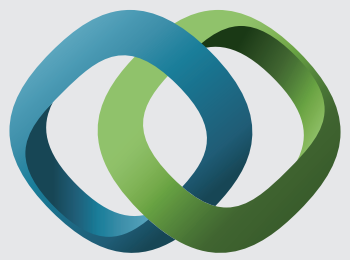

\section{Hindawi}

Submit your manuscripts at

https://www.hindawi.com
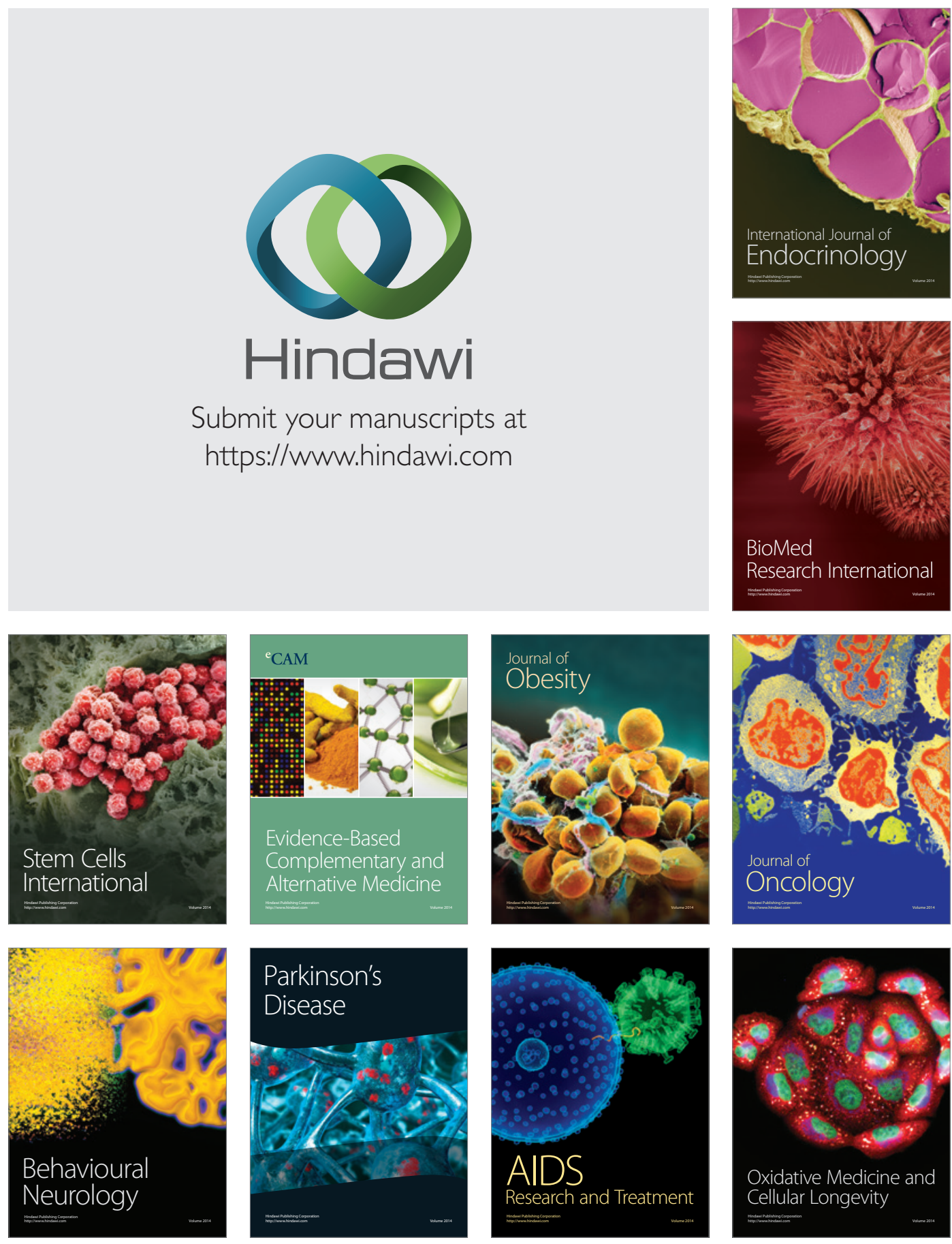